comet is probably well known to many, who will recollect the form of Donati's comet. Although, as you know, that comet appeared only about ten years ago, unfortunately it came too early for us to learn anything about it by means of the spectroscope. We have, first of all, an extremely bright nucleus; then a kind of semilune of greater brilliancy than the rest of the head; then what is called the coma, and the tail. The question which the spectroscope had to put to the comet was-of what is the nucleus composed, and of what is the tail composed. Prof. Donati, and Mr. Huggins especially, to whom we owe so much fur his work in this direction, has made some observations on two small comets-I am sorry they were not larger-with considerable success. He found that in the comets he examined, the head gave out a light which very strongly indeed resembled the spectrum of carbon vapour. The spectrum of carbon taken with the spark in olive oil and in olefiant gas differs slightly; the spectrum as obtained from the latter consists of three bands or waves of light, which commence tolerably bright and sharply on the red side, and become gradually fainter towards the more refrangible side. These bands are severally situated in the beginning of the green, in the true green, and in the blue portions of the spectrum. Mr. Huggins has also observed the spectrum of Encke's comet, and has confirmed the result that he previously obtained, viz., that the spectrum of the comet is identical with the spectrum of carbon, as taken in a hydrocarbon. I should like to draw your attention, if there were time, to the way in which these spectra of the carbon spark taken in oil and in olefiant gas, differ.

I have not yet completed all I have to say on the subject of radiation. If, as we have already seen, we take a tube containing incandescent hydrogen and pass a series of intense electric sparks through it, we see that it gives out a red light, which may remind you of some otlier specimens of radiation which is supplied us by the skies. I allude to the red prominences which are seen around the sun, not in ordinary times, but when the sur. is eclipsed. This representation gives you a good idea of what really is seen when the sun is eclipsed, when we have as it were a black sun instead of a bright one, which is really nothing, but the body of the moon. Around this we have a ring of light, which is called the corona, and here and there in this corona we have what are called red flames and red prominences. These red prominences have also on closer observation been found to be only local aggregations or heapings up of a red layer which surrounds the outer edge of the sun. Here, then, it was quite possible that if the newly invented spectroscope were set to question these things, we should see at once whether they were solid or liquid, or whether they were gaseous or vaporous. If we got a continuous spectrum from these red things, we should know that they were solid, or liquid, or densely gaseous. If, on the contrary, we got a bright line spectrum we should know we were dealing with a gas or vapour. You also see that, as the light is red, the chances were that they were not solid or liquid, and then you further see that if the things do consist of a light which does give us lines, a determination of the exact position of the lines, and a comparison of these positions with those of hydrogen, sodıum, magnesium, barium, or anything else, would teach us what these things were.

J. NORMAN LOCKYER

\section{PROF. FLOWER'S HUNTERIAN LECTURES} LECTURES XIII. XIV. XV.

$T A P I R I D A E$. The geographicaldistribution of the existing members of this small order is very peculiar, they being confined to the Malay Peninsula, Sumatra, and most of South America. Lund has found their remains in the Post-pleistocene caves of Brazil ; they have also been obtained in abundance from similar deposits in North America, and these can hardly be distinguished from those at present existing ; in China likewise Pleistocene Tapir's teeth have been found. In Europe during the same time they do not seem to have existed, although Elephants and Rhinoceroses were abundant. In the Pliocene and Miocene, Tapirs are not unfrequently met with at Eppelsheim, Auvergne, and elsewhere ; perhaps they originated in Europe, and thence spread east into Asia, and on to America. Respecting their anatomical peculiarities, the teeth are forty-two in number, the anterior lower premolar being absent; the molars and premolars are much alike, forming a uniform series; the incisors are smaller than the canines, they have a small cingulum. The molars are a modification of those of Lophiodon, the transverse ridges are very prominent, and the cusp of the cingulum is less developed. The lower possess two simple transverse ridges, as in Lophiodon, but the last in the series wants the extra back lobe. The anterior nares are very open and the orbit is incomplete behind. There are four toes on the front foot, and three behind; the radius and ulna as well. as the tibia and fibia are quite separate and well developed ; $T$. bairdi is peculiar in that the mesethmoid cartilage is well ossified, and the maxillaries are specially developed upwards to support it.

The Palceotheridee occur in the Upper Eocene only, they were first found at Montmartre and worked out by Cuvier; since that time they have been obtained from many parts of France, the Bembridge clay, near Yarmouth, in the Isle of Wight, and in Hampshire. Several genera have been separated off, and about a dozen species, from the size of a small rhinoceros downwards. In general aspect they must have been tapir-like. The maxilla curved downwards in front as in the tapirs; the orbital and temporal fossæ were also united, and there were large anterior osseous nares; the feet were much like those of the tapir, though they were more specialised in wanting the fifth toe to the manus. The typical fortyiour teeth were present ; the incisors were more uniform than in the tapirs; the first pre-molar was rather rudimentary, the others formed a uniform series with the molars, which were wider than from before backwards, much pressed together, and with short crowns. They can be shown to have been developed on the type of Lophiodon, the outer wall bulging inwards, opposite the outer cusps, instead of outwards, giving the earliest indication of the lunate type of tooth; the transverse ridges were normal, and the internal cusps were slightly cut off from them, turning backwards as the rudiments of the posterior semilunes. The lower teeth presented a peculiarity here first noticed, each being formed by a double crescent, quite different from those of the tapir. The last lower molar had a third crescent behind as in Lophiodon and the Artiodactylata, but, different from the latter, in the corresponding milk tooth not presenting it. Palaplotherium was a smaller and earlier genus described by Owen from Hordle. In the upper jaw the first premolar was missing, and the corresponding lower one soon lost; the others were comparatively simple. The remains are very abundant, the feet were as in Palæotherium. Gervais has given the name Propalaotherium to a few teeth of another early form, intermediate between Lophiodon and Palæotherium. Anchitherium was an American form closely allied to the strictly European Palæotheridæ.

Rhinocerotida are at present found in Africa and South Asia only; they belong to three types, the African two: horned, non-scutellated ; the Asiatic two-horned, and the Asiatic single-horned. The extinct members were numerous; four species existed in England. They did not appear before the Miocene epoch; many are found in America, but not above the Pliocene period. The existing genera have peculiarities in their incisor dentition; these teeth are quite absent in the African, and two above as well as below in the Indian species; when they are 
present the outer upper and the inner lower are rudimentary. The canines are absent in all ; the full complement of molars are present, of similar character, and degenerating at either end ; they are formed on the Lophiodon type; the outer wall is very strong and oblique, with the cusps but little developed and the cingulum large behind ; the posterior transverse ridge sends forward a process from near its middle, which in one fossil species ( $R$. tichorhinus) is met by another from the anterior wall to form a circular foramen behind the anterior fossa. The lower molars agree with those of Palæotherium, being formed of a double crescent, in which the posterior cornu of the front lunule is partially overlapped by the anterior cornu of the hind one; no third crescent is found on the last molar; three toes are present on all the limbs. They have not been found fossil in the Eocene strata, consequently the American species are among the earliest. Leidy has named an allied genus of small size Hyracodon. Its teeth resembled rhinoceros, but the anterior premolars were retained; the peculiar uncus on the posterior transverse ridge was wanting, and the proportions of the incisors were reversed. There are several extinct species of the genus Rhinoceros. Acerotherium possessed the same number of teeth as the Asiatic genera, but the nasal bones were small, slender, and smooth above, so they could scarcely have carried a horn; it is a Miocene form only; a fifth rudimentary toe was present. Except $R$. pleuroceros, which had two laterally-placed tubercles on the nasal bones, all the other species had them median. They may be divided by their incisors, as are the recent genera, some having them rudimentary, others not. All the European specimens had two horns, with or without functional incisors. The English species, which are not peculiar, are from Pliocene and Pleistocene formations; in $R$. leptorhinus the nasal septum was not ossified; in others it was much so, as in $R$. tichorhimus, a species which has been found preserved by ice in the river Vilni, a branch of the Lena, in Siberia ; it possessed a hairy coat and the peculiar pit in the molars mentioned above.

From Port St. Julian, in Patagonia, Mr. Darwin first obtained bones of the peculiar genus Macrauchenia, which has not been found out of South America, and only in the Pleistocene deposits there. Prof. Huxley has proved the existence of a second smaller species from some fragments out of a copper mine in Bolivia. Owen showed in his, the first description of the animal, that the vertebræ were peculiar, and agreed with those of the Camels in having the vertebral artery threading a bony canal inside the spinal column, instead of through the bases of the transverse processes. It may be remarked that Myrmecophaga exhibits a similar conformation. But these vertebræ in Macrauchenia are further peculiar in having both ends of the centra quite flat instcad of their being opisthocœlous, as in the allied forms. M. Bravard, who was killed in the earthquake at Mendoza, left excellent drawings of the skull and other parts of this animal, which Prof. Burmeister has since published. From them we learn that the skull was not unhorselike; the orbital ring was complete; the palate was not fully ossified between the posterior molars (the camels present the same peculiarity, though Artiodactylate); the nasal bones were extremely reduced, so that the anterior nares were directly above the posterior, and the lower jaw had the angle prolonged. Burmeister thinks, and with good reason, that the animal possessed a fair-sized trunk. There were twenty-four dorso-lumbar vertebræ, of which seventeen were dorsal. The radius and ulna, as well as the tibia and fibula, were fused throughout. The femur possessed an extremely small third trochanter; and there were three toes to each limb. The astragalus was strongly Perissodactylate, no cuboid facet being present. Our knowledge of the teeth is somewhat deficient, as they are always preserved in a much worn state. The typical forty-four were present ; the incisors were equine, and the canines of the same size; the back. molars were the bigger and the anterior premolars comparatively simple. The lower molars formed double crescents, as in Palæotherium.

In tracing back the descent of the Equida, the Palæotherium d'Orleans of Cuvier has been shown to be generically different, and has been called Anchitherium ; it is also found in Nebraska. These were small horse-like animals with teeth much as in Palæotherium, forty-four in number; the first premolars were very small, and no pit was present in the incisors ; the outer wall of each molar was also concave opposite the cusps; the lower molars formed double crescents, and the last possessed the extra lobe. The ulna and fibula were fused with the radius and tibia respectively; the astragalus had some of the obliqueness of that of the horse, which it resembled in many other points. But there were three toes on the limbs, the lateral ones being less strong than the median. A peculiar antorbital fossa was present.

The horse must be described before the affinities of its close allies can be realised. In it the incisors possess the well-known pit; the canines are rudimentary in the mare; the premolars resemble the molars, and the crowns are very long and deeply embedded, with a concave crescent opposite the tubercles on the outer wall and the anterior internal tubercle insulated at first; otherwise they are typical. The depressions are very deep and are filled up by cementum, to form a solid mass. The lower molars are slightly complicated double crescents. The ulna and fibula are not free. Hipparion had very horse-like teeth. It is a later Miocene form, and is common in the New and Old World. It possessed the antorbital pit, as in Anchitherium, but was otherwise very equins. The canines were present in both sexes of equal size, and the anterior internal tubercle of the molars was completely insulated. The median of the three digits alone was functional. Merychippus, a Pliocene form, recognised by Leidy from some teeth, seems to have been an intermediate form between these and Anchitherium. Fossil true horses abound in America as well as the Old World; they since became extinct in the former locality. They are found in the Pleistocene nearly everywhere ; their earliest remains are from the Sevalik Hills.

With these animals the description of the fossil Perissodactylata terminates.

\section{PERCEPTION IN THE LOWER ANIMALS}

ETTERS on this interesting subject still continue to pour in upon us in so great abundance that limited space compels us to select merely the facts contained in each. The best service we can at present render to the unravelling of the, we think, yet unsolved problem is simply to accumulate facts; no doubt a satisfactory explanation will by-and-by be arrived at. First we must give place to Prof. Croom Robertson, who thus writes as to the theory broached in his former letter :-

In my former letter I made no pretension to explain all the wonderful feats reported of dogs or other animals, but only argued, in the wake of Mr. Wallace, that it had never been sufficiently considered what help in finding their way dogs might have from smell alone. Be the help what it may in the particular cases, I thought it clear that, if in their common experience smell does not somehow supply to dogs the defect of touch, they are, as far as we can see, badly fitted out, by comparison with men, for making their way through the world. And, even after your article of last week, I must still in their interest hope that the notion of a continuous world of smells is not an impossible one.

If the external world were the same to dogs that it is to mena complex of interwoven touches and sights in space, and only in addition dogs had more frequent and varied experiences of smell, the dying away or shifting of some in a particular train of odours would doubtless, as the writer of the article urges, put a dog out 